Pesq. Vet. Bras. 37(10):1133-1138, outubro 2017 DOI: $10.1590 / \mathrm{S} 0100-736 \mathrm{X} 2017001000015$

\title{
Comparison of continuous intravenous infusion of tramadol and tramadol-lidocaine-ketamine in the sevoflurane requirement in $\operatorname{dog} s^{1}$
}

\author{
David R.P. Travagin²* Lianna G. Gomes ${ }^{3}$, Thalita P.P.S. Cruz³, Daiane C. Winter ${ }^{3}$, \\ Fabíola N. Flôres ${ }^{4}$ and Luciana D. Guimarães ${ }^{5}$
}

\begin{abstract}
Travagin D.R.P., Gomes L.G., Cruz T.P.P.S., Winter D.C., Flôres F.N. \& Guimarães L.D. 2017. Comparison of continuous intravenous infusion of tramadol and tramadol-lidocaine-ketamine in the sevoflurane requirement in dogs. Pesquisa Veterinária Brasileira 37(10):1133-1138. Faculdade Integrado de Campo Mourão, Rodovia BR-158 Km 207, Campo Mourão, PR 87300-970, Brazil. E-mail: david.travagin@grupointegrado.br

The objective of this study was to compare the influence of continuous intravenous infusion of tramadol alone, or tramadol combined with lidocaine and ketamine, on minimum alveolar concentration of sevoflurane (MACsevo) of dogs undergoing an ovariohysterectomy (OHE). We used 28 healthy dogs of various breeds and age, randomly divided into two groups according to the infusion given: TRA (tramadol alone) or TLK (tramadol, lidocaine and ketamine). The patients were premedicated with acepromazine and midazolam, and then anesthesia was induced with propofol and maintained with sevoflurane. Fifteen minutes after induction, the patients received their loading dose of treatment. Then, the continuous infusion was then set to $1.3 \mathrm{mg} / \mathrm{kg} / \mathrm{hour}$ of tramadol with or without $3 \mathrm{mg} / \mathrm{kg} /$ hour of lidocaine and $0.6 \mathrm{mg} / \mathrm{kg} /$ hour of ketamine, diluted in a $500 \mathrm{~mL}$ bag of saline solution at an infusion rate of $10 \mathrm{~mL} / \mathrm{kg} /$ hour. The Dixon method was chosen to determine the MACsevo and a skin incision was used as a noxious stimulus. An unpaired Student's t-test was used to identify statistically significant differences between the treatments. These differences were considered significant when $\mathrm{p}<0.05$. The MACsevo of the TRA group was $1.22 \pm 0.15 \mathrm{vol} \%$ and the MACsevo of the TLK group was $0.85 \pm 0.22 \mathrm{vol} \%$. We conclude that TLK infusion decreased the MACsevo by $30.22 \%$ compared to tramadol alone, demonstrating that the combination of drugs was effective in reducing MACsevo in dogs.
\end{abstract}

INDEX TERMS: Tramadol, tramadol-lidocaine-ketamine, sevoflurane, dogs, analgesia, anesthesia, inhalant, MAC.

RESUMO.- [Comparação da infusão continua intravenosa de tramadol e de tramadol-lidocaína-cetamina no requerimento de sevofluorano em cães.] 0 objetivo

\footnotetext{
${ }^{1}$ Received on July 26, 2016.

Accepted for publication on December 2, 2016.

${ }^{2}$ Departamento de Medicina Veterinária, Faculdade Integrado de Campo Mourão, Rodovia BR-158 Km 207, Campo Mourão, PR 87300-970, Bra-

zil. *Corresponding author: david.travagin@grupointegrado.br

${ }^{3}$ Programa de Mestrado em Ciência Animal, Universidade Federal de Mato Grosso (UFMT), Av. Fernando Correa da Costa 2367, Boa Esperança, Cuiabá, MT 78060-900, Brazil.

${ }^{4}$ Faculdade de Medicina Veterinária, Universidade Federal de Roraima (UFRR), Boa Vista, RR 69310-000, Brazil.

${ }^{5}$ Departamento de Anestesiologia, Faculdade de Medicina Veterinária, UFMT, Cuiabá, MT 78068-900, Brazil.
}

deste estudo foi comparar a influência da infusão contínua intravenosa do tramadol isolado e associado com lidocaína e cetamina, na concentração alveolar mínima de sevofluorano (CAMsevo) em cadelas submetidas à ovariosalpingohisterectomia. Foram utilizados 28 animais saudáveis de várias raças e idades, divididos aleatoriamente em dois grupos de acordo com a infusão adminstrada: TRA (tramadol) ou TLK (tramadol, lidocaína e cetamina). A medicação pré-anestésica foi realizada com acepromazina e midazolam, em seguida, a anestesia foi induzida com propofol e mantida com sevofluorano. Quinze minutos após a indução, os pacientes receberam um bolus do tratamento, com a infusão continua iniciada logo em seguida, sendo $1,3 \mathrm{mg} / \mathrm{kg} /$ hora de tramadol, associado ou não a $3 \mathrm{mg} / \mathrm{kg} /$ hora de lidocaína e $0,6 \mathrm{mg} / \mathrm{kg} / \mathrm{hora}$ de cetamina, diluidos em uma bolsa 
de solução salina de $500 \mathrm{~mL}$ a uma taxa de infusão taxa de $10 \mathrm{ml} / \mathrm{kg} /$ hora. 0 método de Dixon foi escolhido para determinar a MACsevo e a incisão na pele foi utilizada como o estímulo nocivo. 0 teste $t$ de Student não pareado foi utilizado para identificar diferenças estatisticamente significativas entre os tratamentos. Estas diferenças foram consideradas significativas quando $\mathrm{p}<0,05$. A CAMsevo do grupo TRA foi de $1,22 \pm 0,15 \mathrm{vol} \%$ e a CAMsevo do grupo TLK foi de $0,85 \pm 0,22 \mathrm{vol} \%$. Conclui-se que a infusão de TLK diminuiu a CAMsevo em $30,22 \%$ em relação ao tramadol isolado, o que demonstra que a combinação de agentes analgésicos foi eficaz na redução do requerimento de sevofluorano em cães.

TERMOS DE INDEXAÇÃO: Tramadol, tramadol-lidocaína-cetamina, sevofluorano, caninos, analgesia, anestesia, CAM, inalatório.

\section{INTRODUCTION}

Drugs of different classes can be utilized together to move a patient through the various aspects of anesthesia, which are analgesia, amnesia, muscle relaxation and blockage of autonomic reflexes, thus achieving and maintaining homeostasis during a medical procedure (Orosz et al. 2012). This technique offers multimodal control in pain management (Ilkiw 1999).

The administration of analgesic agents via continuous intravenous (IV) infusion during the perioperative period is becoming a good choice method because it allows for increased pain control and decreases the requirement for inhalant anesthetics to maintain anesthesia (Matsubara et al. 2009, Muir 2010, Fajardo et al. 2012).

Continuous infusion of lidocaine and ketamine has been widely used in veterinary medicine to ensure effective analgesia because when combined, these drugs act on different receptors present in the pain pathways. This effect may be increased by adding an opioid, as they are capable of promoting sedation in addition to being potent analgesics (Koppert 2004). Studies have shown that the combination of ketamine, lidocaine along with morphine or fentanyl in a continuous infusion decreased the minimum alveolar concentration (MAC) of inhalational anesthetic agents in horses (Muir 2010, Villalba et al. 2011) and dogs (Wilson et al. 2008, Aguado et al. 2011).

Ketamine is a noncompetitive antagonist of the N-methyl-D-aspartate (NMDA) receptors, but has some effect on opioid and muscarinic receptors and calcium channels (Kawamata et al. 2000).

Lidocaine is a local anesthetic widely used for local blockage of pain and can be used IV. Lidocaine acts on the internal surface of the sodium channel, preventing the transmission of the action potential by the axon, causing stabilization in a standby state. It has effects on G protein-coupled receptors and NMDA receptors (Skarda \& Tranquilli 2007). Muir et al. (2003) demonstrated that lidocaine reduces the need for isoflurane in dogs by $29 \%$ when used as part of an IV continuous infusion. Valverde et al. (2004) found an $18 \%$ reduction with the same drug.

Tramadol is a synthetic analogue of codeine with central action and selectivity for mu $(\mu)$ opioid receptors. It blocks the re-uptake of the neurotransmitters norepinephrine and serotonin (Cagnardi et al. 2011). Its analgesic potency is similar to meperidine and five to 10 times less than morphine (Collart et al. 1993). It is the opioid with fewest side effects (Close 2005).

Sevoflurane is a halogenated inhalation anesthetic agent with MAC of 2.1 to $2.3 \mathrm{vol} \%$ in dogs and a coefficient of blood:gas solubility of 0.6 , which ensures rapid induction and recovery from anesthesia (McKelvey \& Hollingshead 2003). It works by depressing the action of the central nervous system, causing amnesia and immobility to noxious stimuli, but it does not enhance analgesia. Its elimination occurs through the lungs, and only $3 \%$ of the inhaled amount is metabolized in the liver (Duarte \& Saraiva 2005).

MAC is a measure of the potency of an inhaled anesthetic, defined as the concentration of anesthetic at one atmosphere required to abolish movements in response to a noxious stimulus in half of the patients tested (Eger et al. 1965).

The method of sequential allocation dependent on the patient's previous response (the up-and-down method) is a statistical method (Dixon 1965) widely used for the determination of a lethal dose of medication (LD50) and the anesthetic minimum volume (MAV) for local anesthetics. It is also used in clinical settings for the determination of MAC in human patients, as it significantly reduces the anesthetic risk by reducing the duration of anesthesia during each individual experiment.

There is little information regarding the use of a continuous infusion of tramadol combined with lidocaine and ketamine, however some studies have suggested that IV or epidural use of tramadol reduced the MAC of inhaled anesthetic agent and/or allowed adequate analgesia (Seddighi et al. 2009; Itami et al. 2013).

This study aimed to compare the effect of an IV continuous infusion of tramadol alone or TLK on the MACsevo in dogs undergoing elective ovariohysterectomy (OHE). Our hypothesis is that the combination of TLK can decrease the inhalant requirement compared to the use of tramadol alone.

\section{MATERIALS AND METHODS}

Ethics statement. The experiment was conducted at the Veterinary Hospital of Federal University of Mato Grosso (HOVET-UFMT), Cuiabá/MT, Brazil, in compliance with the Ethics Principles in Animal Experimentation, being approved by the Ethics Committee on Animal Experimentation (CEUA/UFMT) (Protocol \#23108.047034/13-6).

Animals. We used 28 dogs, of various breeds, that were admitted for elective OHE to the HOVET-UFMT. All pet owners signed a consent form to participate in this study. The dogs received a physical examination, complete blood count and serum biochemistry and were considered healthy for participation. Only dogs between 1 and 6 years old (large breeds) or 8 (small and medium breeds) were admitted to participate in the study. After prior fasting (eight hours with no food and three hours with no water), dogs were premedicated with intramuscular acepromazine $0.05 \mathrm{mg} /$ $\mathrm{kg})$ and midazolam $(0.25 \mathrm{mg} / \mathrm{kg})$. After 30 minutes, the operative field and dorsal aspect of the forelimb were shaved. A catheter was inserted into the cephalic vein, through which a prophylactic dose of cephalothin $(25 \mathrm{mg} / \mathrm{kg})$ and fluid therapy were administe- 
red. Propofol IV $(5.7 \pm 0.4 \mathrm{mg} / \mathrm{kg})$ was administered to effect over two minutes to induce anesthesia. Anesthesia was maintained with sevoflurane, in a calibrated vaporizer, diluted in a flow of $20 \mathrm{~mL} / \mathrm{kg} /$ minute of $100 \%$ oxygen through a circular semi-closed system. Controlled ventilation was performed with a tidal volume of $10-12 \mathrm{~mL} / \mathrm{kg}$, respiratory rate of eight breaths per minute and airway pressure between 10 and $20 \mathrm{~cm} \mathrm{H} 20$ to maintain the carbon dioxide exhaled at 30-40mmHg. During anesthesia, patients were positioned in dorsal recumbency on a warming blanket to maintain body temperature.

Cardiovascular and respiratory variables were monitored throughout the anesthesia with a multiparameter monitor (PM9000 Mindray Express, China). A capnography sensor and a side-stream anesthetic gas analyzer were attached to the connection between the endotracheal tube and the circle circuit allowing for the measurement of expired sevoflurane, expired $\mathrm{CO}_{2}$ and the respiration rate. The capnograph and the gas analyzer were calibrated before each experiment with a standardized calibration gas mixture (1\% sevoflurane, $5 \% \mathrm{CO}_{2}, 60 \% \mathrm{~N}_{2}$ ) (Quick Cal Calibration Gas; Datex-Engstrom Division Instrumentarium Co., Finland). A pulse oximeter sensor was placed on the animal's tongue to check the oxygen saturation of hemoglobin. Electrodes were attached to the skin of the animals to monitor the electrocardiographic tracing and heart rate in the standard way for dogs. The systolic, diastolic and mean blood pressures were measured by oscillometry. This entailed placing a cuff that was sized to approximately $40 \%$ of the forelimb diameter (PetMAP, Ransey Medical, FL, USA). An esophageal thermometer verified the animal's temperature.

Experimentation. The patients were randomly divided into two groups. Randomization was performed by drawing one of two pieces of paper with each treatment identification from a bag. The first group received TRA (tramadol) alone and the second group received TLK (tramadol + lidocaine + ketamine). After 15 minutes of induction, the patients received their loading doses of treatment: $2 \mathrm{mg} / \mathrm{kg}$ of tramadol (Kukanich \& Papich 2004) for both groups and $1 \mathrm{mg} / \mathrm{kg}$ of lidocaine and $0.25 \mathrm{mg} / \mathrm{kg}$ of ketamine (Dyson 2008) for TLK group, combined in a single syringe and administered manually over approximately three minutes. The continuous infusion was then set to $1.3 \mathrm{mg} / \mathrm{kg} / \mathrm{hour}$ of tramadol (Seddighi et al. 2009), with or without $3 \mathrm{mg} / \mathrm{kg} / \mathrm{hour}$ of lidocaine and $0.6 \mathrm{mg} / \mathrm{kg} /$ hour of ketamine (Muir et al. 2003), according to the treatment group, diluted in a $500 \mathrm{~mL}$ bag of saline solution at an infusion rate of $10 \mathrm{~mL} / \mathrm{kg} /$ hour, controlled by a linear infusion pump (Mindray SK 600, China). The solution was prepared right after the premedication was given to the patients.

At the end of the surgery, the vaporizer was turned off and the continuous infusion of the solution was terminated followed by the administration of meloxicam $(0.2 \mathrm{mg} / \mathrm{kg}) \mathrm{IV}$. Only one surgeon was responsible for conducting the OHE.

Determination of sevoflurane MAC. Dixon's up-and-down method (1965) was chosen to determine the MAC of sevoflurane. In this method, the response, positive or negative, to the noxious stimulus is recorded only once for each animal, and the results are based on all animals tested. Thirty minutes after the initial bolus and initiation of infusion, and at least 20 minutes after the stabilization of the end-tidal concentration of sevoflurane (ETsevo), the skin incision was made to determine the MAC. The response to the stimulus was considered positive if the animal made any gross movement of the head or limbs (Ewing et al. 1993). The ETsevo set for the first animal of the TRA group was defined as $1.8 \mathrm{vol} \%$ and for the first animal in the TLK group was $1.4 \mathrm{vol} \%$ (Wilson et al. 2008, Itami et al. 2013). When the animal responded negatively (no movement), the ETsevo for the next animal was reduced by $0.1 \mathrm{vol} \%$. When the response was positive (the animal moved) the ETsevo was increased by 0.1 vol\% for the next animal. Changes in the response to pain stimuli between two consecutive animals a positive response followed by a negative response, or vice versa - were defined as crossover values. The ETsevo tested in four crossovers, in which the same dog could not appear twice (ETsevo values from eight different dogs), were used to calculate the MACsevo value in each group by mathematical averaging (Aguado et al. 2011, Wadhwa et al. 2003).

The MAC values were adjusted to values at sea level (MACsl) using the equation: MACsl $=$ (barometric pressure local/760mmHg) x MAC obtained.

After the MAC determination, when necessary, a bolus of propofol was given and the ETsevo was increased by $0.5 \mathrm{vol} \%$ to provide the a necessary depth of anesthesia for the OHE surgery.

Statistical analysis. Data distribution was analyzed using the D’Agostino normality test. Data are presented as mean \pm SD and differences between groups were considered significant when p $<0.05$ using GraphPad Prism 6 (CA, USA). An unpaired Student's t-test was used to test for statistically significant differences between treatments. Blood pressure values were submitted to repeated measures as an analysis of variance.

\section{RESULTS}

There were no statistical differences between the two groups when considering age, weight, body temperature, Sp02 or blood pressure values (Table 1). The MACsevo of the TRA group was $1.22 \pm 0.15 \mathrm{vol} \%$ and the MACsevo of the TLK group was $0.85 \pm 0.22 \mathrm{vol} \%$. The combination of tramadol with lidocaine and ketamine decreased the MACsevo by $30.32 \%$ compared to tramadol alone $(\mathrm{p}<0.0001)$. These data provide $97.8 \%$ power to detect any difference between the groups.

The ETsevo values for each animal can be seen in Figure 1 . Of the four animals in the TRA group that moved in response to noxious stimuli, all showed movements in the hind limbs. In TLK group two animals moved the hind limbs, one animal moved the forelimb and one of them moved both limbs. In none of the animals head movement was observed.

\section{DISCUSSION}

The combination of injectable drugs considerably reduced the need for sevoflurane to maintain anesthesia in dogs. For ethical reasons, we chose not to create a control group

Table 1. Characteristics of patients and potential confounding factors in dogs premedicated with acepromazine and midazolam anesthetized with sevoflurane administered an intravenous continuous infusion of tramadol [TRA; loading dose (2 mg/ $\mathrm{kg}$ ) and infusion (1.3 mg/ $\mathrm{kg} / \mathrm{hour})]$ or tramadollidocaine-ketamine [TLK; tramadol loading dose $(2 \mathrm{mg} / \mathrm{kg})$ and infusion of tramadol (1.3 mg/ $\mathrm{kg} / \mathrm{hour})$, lidocaine (3 mg/ $\mathrm{kg} / \mathrm{hour})$ and ketamine $(0.6 \mathrm{mg} / \mathrm{kg} / \mathrm{hour})]$. Values are mean \pm standard deviation. None of the values showed a statiscally difference ( $p>0.05$ ). Blood pressure (oscillometry) and SpO2 values obteined at the time of skin incision

\begin{tabular}{lcc}
\hline Variable & \multicolumn{2}{c}{ Group } \\
\cline { 2 - 3 } & TRA (n=14) & TLK $(\mathrm{n}=14)$ \\
\hline Age (years) & $4 \pm 0.58$ & $4 \pm 0.53$ \\
Weight (Kilograms) & $11.7 \pm 1.91$ & $12.3 \pm 1.80$ \\
Esophageal temperature $\left({ }^{\circ} \mathrm{C}\right)$ & $37.7 \pm 0.2$ & $37.8 \pm 0.4$ \\
$\mathrm{SpO}_{2}(\%)$ & $99.64 \pm 0.13$ & $99.65 \pm 0.12$ \\
Mean arterial blood pressure (mmHg) & $86 \pm 7$ & $85 \pm 9$
\end{tabular}



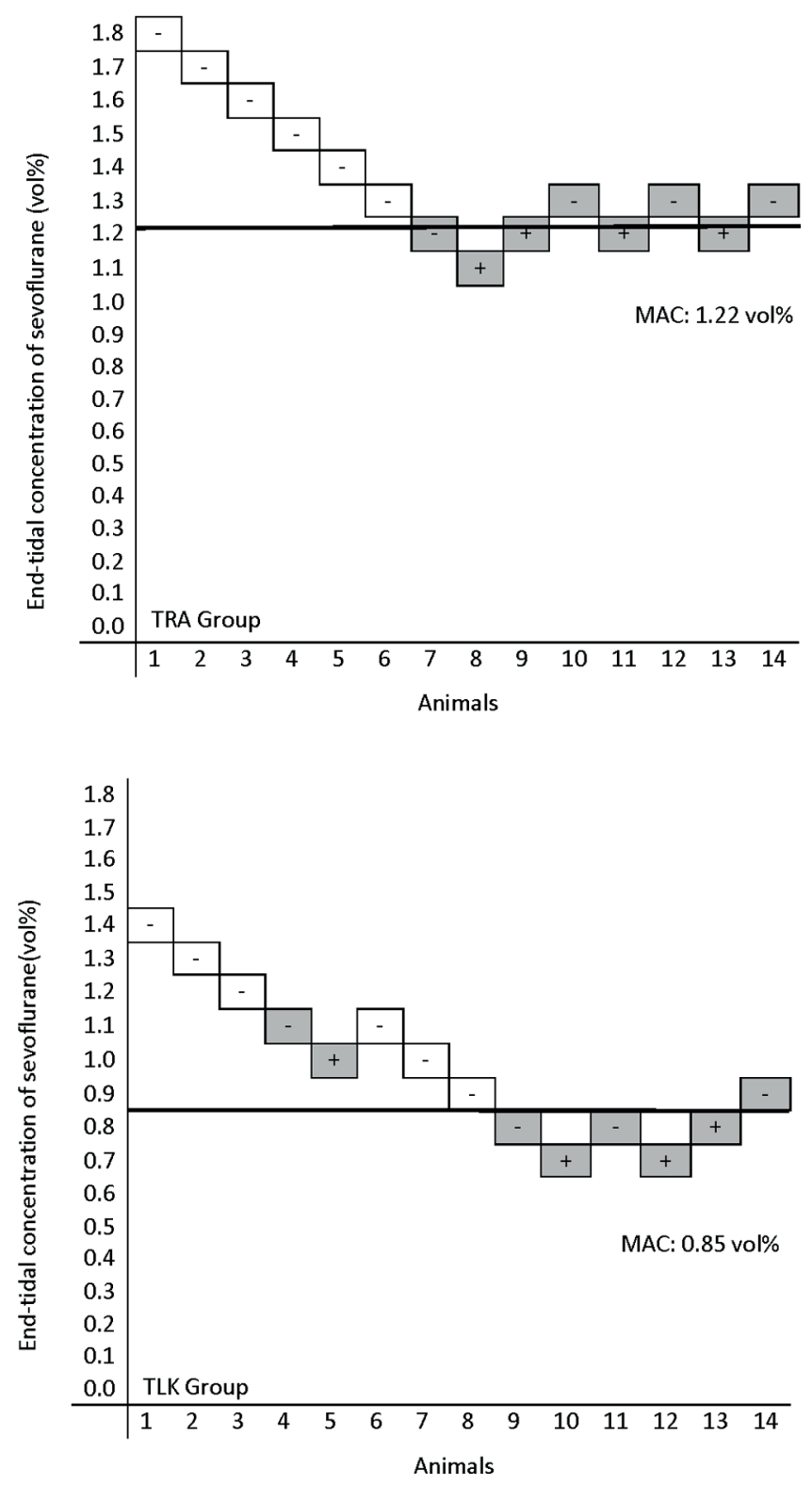

Fig.1. End-tidal concentration of sevoflurane in dogs premedicated with acepromazine and midazolam anesthetized with sevoflurane administered an intravenous continuous infusion of tramadol [TRA; loading dose $(2 \mathrm{mg} / \mathrm{kg})$ and infusion $(1.3 \mathrm{mg} /$ $\mathrm{kg} /$ hour)] or tramadol-lidocaine-ketamine [TLK; tramadol loading dose $(2 \mathrm{mg} / \mathrm{kg})$ and infusion of tramadol $(1.3 \mathrm{mg} / \mathrm{kg} /$ hour), lidocaine $(3 \mathrm{mg} / \mathrm{kg} /$ hour $)$ and ketamine $(0.6 \mathrm{mg} / \mathrm{kg} /$ hour)], that did or did not move, in response to the skin incision. (+) Indicates a positive response (movement); (-) indicates a negative response (no movement). Grey squares indicate the crossover values. Lines indicate the calculated MAC by up-and-down method.

without infusion of analgesic agents, since patients undergoing this surgical experiment were routine hospital patients.

Several studies have evaluated the effect of drugs combinations administered by continuous IV infusion on the requirement for inhalational agents. Studies with sevoflurane have obtained different basal MAC: $2.2-2.3$ vol\%
(Matsubara et al. 2009, Columbano et al. 2012) and 1.82$1.9 \mathrm{vol} \%$ (Wilson et al. 2008, Itami et al. 2011, Itami et al. 2013, Moran-Muñoz et al. 2014). This variation may be due to methodological differences, since various stimuli can be applied, such as electrical stimulation, surgical incisions, digital pressure, tail clamping or movement of the endotracheal tube (Ebert \& Schmid 2004). Alternatively, the variation may be due to differences in the drugs used.

The MAC reduction found in this study is similar to the one reported by Itami et al. (2013), who obtained MAC reduction of 1.86 to $1.44 \mathrm{vol} \%$, (approximately 22\%) after the administration of tramadol in a single dose. In a study with rats (Wolff et al. 1999), it was observed that tramadol could reduce the MAC of isoflurane. Despite the known efficacy of tramadol as an intra- and postoperative analgesic with minimal cardiorespiratory adverse events (Vettorato et al. 2010, Cagnardi et al. 2011, Fajardo et al. 2012, Kogel et al. 2014), there is little information about its effects on the MAC of inhalational anesthetics.

The combination of tramadol with lidocaine and ketamine promoted a significant decrease in the sevoflurane MAC, by approximately $30 \%$ when compared to tramadol alone. Previous studies have shown that the use of IV infusions of lidocaine, ketamine, or both combined, are capable of promoting reduction of MAC of isoflurane and sevoflurane. Moran-Muñoz et al. (2014) demonstrated a reduction of sevoflurane MAC of $27 \%$ (from $1.82 \mathrm{vol} \%$ to $1.38 \mathrm{vol} \%$ ) in dogs using lidocaine and ketamine. Similarly, Wilson et al. (2008) obtained a reduction of $22 \%$ to $39 \%$ using a lidocaine infusion at different doses. These authors also demonstrated a decrease in the MAC of sevoflurane by between $40 \%$ and $44 \%$ using infusions of ketamine in low and high doses in dogs. When the two drugs were combined, a reduction of approximately $63 \%$ in the MAC of sevoflurane was achieved.

Studies with lidocaine and ketamine have demonstrated similar reductions in the MAC of isoflurane in dogs; Gutierrez-Blanco et al. (2013) obtained a reduction of $22 \%$ with lidocaine; Valverde et al. (2004) found an 18\% reduction; and Muir et al. (2003) obtained a 29\% reduction. The use of these drugs, as well as reducing MAC, can offer other benefits such as improved sedation and anti-hyperalgesic effects (Gutierrez-Blanco et al. 2013).

The administration of acepromazine and midazolam as a premedication regimen may have influenced our MAC values. Most MAC studies only use the drugs to be evaluated, but because our experiment was being performed on animals in a veterinary hospital, we opted for the use of premedication. The acepromazine has a long plasma half-life (Hashem et al. 1992) and may have reduced the inhalational anesthetic requirement throughout the study. Heard et al. (1986) demonstrated a 34\% reduction in halothane requirement in dogs that received acepromazine while Monteiro et al. (2016) achieved a reduction in the MAC of isoflurane by $33.3 \%$ in dogs premedicated with acepromazine and morphine. Midazolam administered by CRI showed a MAC reduction by 11\% (Seddighi et al. 2011). However, both groups received the same premedication protocol.

We used a skin incision for determining the MAC of se- 
voflurane. Although this is not the supramaximal noxious stimulus for dogs compared to electrical stimulation or clamping of the tail, it is a reliable method because it mimics the clinical situation. Aguado et al. (2011), using the same method, found lower isoflurane MAC than that reported by Muir et al. (2003), using the same doses of lidocaine, ketamine and morphine, but the proportional MAC reductions were similar.

Four crossovers were considered adequate for MAC estimation as it is reported that the MAC values obtained from four crossovers is nearly the same as the MAC values obtained from a larger number of crossovers (Paul \& Fisher 2001).

The use of drugs infusions allows a reduction of the need for inhalational agents, and consequently decreases cardiorespiratory depression, ensures a constant level of analgesia, avoids peak plasma concentrations associated with intermittent administration, and allows the use of smaller doses, which should decrease side effects (Fajardo et al. 2012).

\section{CONCLUSIONS}

A continuous infusion of tramadol resulted in a sevoflurane requirement of $1.22 \mathrm{vol} \%$ in dogs premedicated with acepromazine and midazolam undergoing OHE.

The addition of lidocaine and ketamine to the tramadol infusion further decreased the sevoflurane requirement by $30.32 \%$ to 0.85 vol $\%$.

We concluded that the combination of drugs was effective in reducing MACsevo in dogs.

Conflict of interest statement.- The authors have no competing interests.

\section{REFERENCES}

Aguado D., Benito J. \& Gómez de Segura I.A. 2011. Reduction of the minimum alveolar concentration of isoflurane in dogs using a constant rate infusion of lidocaine-ketamine in combination with either morphine or fentanyl. Vet. J. 189:63-66.

Cagnardi P., Villa R., Zonca A., Gallo M., Beccaglia M., Luvoni G.C., Vettorato E., Carli S., Fonda D. \& Ravasio G. 2011. Pharmacokinetics, intraoperative effect and postoperative analgesia of tramadol in cats. Res. Vet. Sci. 90:503-509.

Close B.R. 2005. Tramadol: does it have a role in emergency medicine? Emerg. Med. Australasia 17:73-83.

Collart L., Luthy C. \& Dayer P. 1993. Multimodal analgesic effect of tramadol. Clin. Pharmacol. Ther. 53:223.

Columbano N., Secci F., Careddu G.M., Stgiu G., Rossi G. \& Driessen B. 2012. Effects of lidocaine constant rate infusion on sevoflurane requirement, autonomic responses, and postoperative analgesia in dogs undergoing ovariectomy under opioid-based balanced anesthesia. Vet. J. 193:448455.

Dixon W.J. 1965. The up-and-down method for small samples. J. Am. Stat. Assoc. 60:967-978.

Dyson D. 2008. Perioperative pain management in veterinary patients. Vet. Clin. North Am., Small Anim. Pract. 38:1309-1327.

Duarte L.T.D. \& Saraiva R.S. 2005. Imobilidade: uma ação essencial dos anestésicos inalatórios. Revta Bras. Anestesiol. 55:18-24.

Ebert T.J. \& Schmid P.G. III. 2004. Anestesia inalatória, p.377-417 In: Anestesia clínica. 4th ed. Manole, São Paulo, Brazil.

Eger E.Z., Saidman L.J. \& Brandstater B. 1965. Minimum alveolar anesthetic concentration: a standard of anesthetic potency. Anesthesiology 26:756-763.
Ewing K.K., Mohammed H.O., Scarlett J.M. \& Short C.E. 1993. Reduction of isoflurane anesthetic requirement by medetomidine and its restoration by atipamezole in dogs. Am. J. Vet. Res. 54:294-299.

Fajardo M.A., Lesmes M.A. \& Cardona L.A. 2012. Evaluación del efecto analgésico postoperatorio de infusiones intraoperatorias de tramadol y tramadol/lidocaína/ketamina en comparación com morfina/lidocaína/ ketamina en hembras caninas sometidas a ovariohisterectomía. Arch. Med. Vet. 44:145-153.

Gutierrez-Blanco E., Victoria-Mora J.M., Ibancovichi-Camarillo J.A., Sauri-Arceo C.H., Bolio-González M.E., Acevedo-Arcique C.M., Marin-Cano G. \& Steagall P.V. 2013. Evaluation of the isoflurane-sparing effects of fentanyl, lidocaine, ketamine, dexmedetomidine, or the combination lidocaine-ketamine-dexmedetomidine during ovariohysterectomy in dogs. Vet. Anaesthesiol. Analg. 40:599-609.

Hashem A., Kietzmann M. \& Scherkl R. 1992. The pharmacokinetics and bioavailability of acepromazine in the plasma of dogs. Dtsch. Tierärztl. Wochenschr. 99:396-398.

Heard D.J., Webb A.I. \& Daniels R.T. 1986. Effect of acepromazine on the anesthetic requirement of halothane in the dog. Am. J. Vet. Res. 47:2113-2115.

Ilkiw J.C. 1999. Balanced anesthetic techniques in dogs and cats. Clin. Tech. Small Anim. Pract. 14:27-37.

Itami T., Tamaru N., Kawase K., Ishizuka T., Tamura J., Miyoshi K., Umar M.A., Inoue H. \& Yamashita K. 2011. Cardiovascular effects of tramadol in dogs anesthetized with sevoflurane. J. Vet. Med. Sci. 73:1603-1609.

Itami T., Kawase K., Tamaru N., Ishizuka T., Tamura J., Miyoshi K., Umar M.A., Inoue H. \& Yamashita K. 2013. Effects of a single bolus intravenous dose of tramadol on minimum alveolar concentration (MAC) of sevoflurane in dogs. J. Vet. Med. Sci. 75:613-618.

Kawamata T., Omote K., Sonoda H., Kawamata M. \& Namiki A. 2000. Analgesic mechanisms of ketamine in the presence and absence of peripheral inflammation. Anesthesiology 93:520-528.

Kogel B., Terlinden R. \& Schneider J. 2014. Characterization of tramadol, morphine and tapentadol in an acute pain model in beagle dogs. Vet. Anaesthesiol. Analg. 41:297-304.

Koppert W. 2004. Perioperative intravenous lidocaine has preventive effects on postoperative pain and morphine consumption after major abdominal surgery. Anesthesiol. Analg. 98:1050-1055.

Kukanich B. \& Papich M. 2004. Pharmacokinetics of tramadol and the metabolite o-desmethyltramadol in dogs. J. Vet. Pharmacol. Ther. 27:239-246.

Matsubara L.M., Oliva V.N., Gabas D.T., Oliveira G.C. \& Cassetari M.L. 2009. Effect of lidocaine on the minimum alveolar concentration of sevoflurane in dogs. Vet. Anaesthesiol. Analg. 36:407-413.

McKelvey D. \& Hollingshead K.W. 2003. Veterinary anesthesia and analgesia, p.448. 3rd ed. Mosby Elsevier, Maryland Heights, USA.

Monteiro E.R., Coelho K., Bressan T.F., Simões C.R. \& Monteiro B.S. 2016. Effects of acepromazine-morphine and acepromazine-methadone premedication on the minimum alveolar concentration of isoflurane in dogs. Vet. Anaesthesiol. Analg. 43:27-34.

Moran-Muñoz R., Ibancovichi J.A. \& Gutierrez-Blanco E. 2014. Effects of lidocaine, dexmedetomidine or their combination on minimum alveolar concentration of sevoflurane in dogs. J. Vet. Med. Sci. 76:847-853.

Muir W.W.T. 2010. NMDA receptor antagonists and pain: ketamine. Vet. Clin. North Am., Equine Pract. 26:565-578.

Muir W.W.T., Wielse A.J. \& March P.A. 2003. Effects of morphine, lidocaine, ketamine, and morphine-lidocaine-ketamine drug combination on minimum alveolar concentration in dogs anesthetized with isoflurane. Am. J. Vet. Res. 64:1150-1160.

Orosz J.E., Braz M.G., Golim M.A., Barreira M.A., Fecchio D., Braz L.G. \& Braz J.R. 2012. Cytokine profile in patients undergoing minimally invasive surgery with balanced anesthesia. Inflammation 35:1807-1813.

Paul M. \& Fisher D.M. 2001. Are estimates of MAC reliable? Anesthesiology 95:1362-1370.

Seddighi M.R., Egger C.M., Rohrbach B.W., Cox S.K. \& Doherty T.J. 2009. Effects of tramadol on the minimum alveolar concentration of sevoflurane in dogs. Vet. Anaesthesiol. Analg. 36:334-340. 
Seddighi R., Egger C.M., Rohrbach B.W., Cox S.K. \& Doherty T.J. 2011. The effect of midazolam on the end-tidal concentration of isoflurane necessary to prevent movement in dogs. Vet. Anaesthesiol. Analg. 38:195202.

Skarda R.T. \& Tranquilli W.J. 2007. Local anesthetics, p.395-418. In: Lumb \& Jones' Veterinary Anesthesia and Analgesia. 4th ed. Blackwell Publishing, Oxford, UK.

Valverde A., Doherty T.J., Hernández J. \& Davies W. 2004. Effect of lidocaine on the minimum alveolar concentration of isoflurane in dogs. Vet. Anaesthesiol. Analg. 31:264-271.

Vettorato E., Zonca A., Isola M., Villa R., Gallo M., Ravasio G., Beccaglia M., Montesissa C. \& Cagnardi P. 2010. Pharmacokinetics and efficacy of intravenous and extradural tramadol in dogs. Vet. J. 183:310-315.
Villalba M., Santiago I. \& Gomez de Segura I.A. 2011. Effects of constant rate infusion of lidocaine and ketamine, with or without morphine, on sevoflurane MAC in horses. Equine Vet. J. 43:721-726.

Wadhwa A., Durrani J., Sengupta P., Doufas A.G. \& Sessler D.I. 2003. Women have the same desflurane minimum alveolar concentration as men. Anesthesiology 99:1062-1065.

Wilson J., Doherty T.J., Egger C.M., Fidler A., Cox S. \& Rohrbach B. 2008. Effects of intravenous lidocaine, ketamine and the combination on the minimum alveolar concentration of sevoflurane in dogs. Vet. Anaesthesiol. Analg. 35:289-296.

Wolff M.H., Leather H.A. \& Wouters P.F. 1999. Effects of tramadol on minimum alveolar concentration (MAC) of isoflurane in rats. Brit. J. Anaesthesiol. 83:780-783. 